\title{
Primer reporte de Neospora caninum, en caballos de carrera de Lima, Perú
}

First report of Neospora caninum, in race horse from Lima, Peru

\author{
María Luza ${ }^{1}$, Enrique Serrano-Martínez1, Manuel Tantaleán ${ }^{1}$, Marco Quispe ${ }^{1}$, Gina Casas ${ }^{2}$

\section{RESUMEN}

Objetivos: Determinar la exposición de los caballos de carrera al $N$. caninum, mediante la detección de anticuerpos séricos. Material y Método: Se evaluaron 163 sueros de caballos procedentes del Hipódromo de Monterrico, Lima, los cuales fueron procesados mediante el método de Inmunoflorescencia Indirecta, considerándose positivos aquellos animales cuyos sueros obtuvieron un título igual o mayor a 1:100. Se realizó la titulación del suero mediante diluciones seriadas hasta alcanzar una dilución negativa. Resultados: Se detectaron anticuerpos a $N$. caninum en el $12 \%(19 / 163)$ de los caballos examinados, $21 \%$ presentaron títulos de $1 / 100,1 / 800$ y $1 / 1600$, el $6 \%$ presentaron títulos de $1 / 200$ y $1 / 400$ y el $5 \%$ presentaron títulos de 1/3200. No se encontró asociación entre las variables sexo, edad y procedencia con la presencia de seroreactores frente a N. caninum. Conclusión: El presente estudio es el primero en confirmar la presencia de anticuerpos séricos a $N$. caninum en caballos de carrera de Perú.

PALABRAS CLAVE: Neospora, protozoo, inmunoflorescencia indirecta, anticuerpos, caballos

\section{SUMMARY}

Objectives: Determine the exposure of $N$. caninum in racehorses with the detection of serum antibodies. Material and methods: We evaluated sera from 163 horses from the Hippodrome of Monterrico, Lima, which were processed using the indirect immunofluorescence method, considering positive animals whose sera obtained a degree equal to or greater than 1:100. Was performed by titrating the serum dilutions to reach a negative dilution. Results: Antibody to $N$. caninum in $12 \%(19 / 163)$ of the horses examined, $21 \%$ had titers of $1 / 100,1 / 800$ and $1 / 1600,6 \%$ had titers of $1 / 200$ and $1 / 400$ and $5 \%$ had titers $1 / 3200$. No association between sex, age and origin with the presentation seroreactors against $N$. caninum. Conclusions: The present study is the first to confirm the presence of serum antibodies to N. caninum in race horses from Peru.

KEY WORDS: Neospora, protozoa, indirect immunofluorecent test, antibody, horse

\section{INTRODUCCIÓN}

Neospora caninum es un parásito protozoo intracelular, del phylum Apicomplexa, estructuralmente parecido a Toxoplasma gondii (1), siendo descrito en 1988 como un nuevo género cuando se reconoció en perros (2).

Este protozoo de tipo coccidia es cosmopolita y presenta un amplio rango de hospederos. El perro y el coyote son los hospederos definitivos, pero también pueden actuar como hospederos intermediarios $(3,4)$. En perros produce desórdenes neuromusculares, parálisis y muerte (5). En los hospederos intermediarios (bovinos, ovejas, cabras, venados y caballos, entre otros) causa abortos y mortalidad neonatal (5). Además, se ha encontrado anticuerpos séricos frente a $N$. caninum en búfalos de agua, zorros, coyotes, camellos, felinos (1), y en alpacas y llamas (6-7).

\footnotetext{
${ }^{1}$ Facultad de Medicina Veterinaria y Zootecnia, Universidad Peruana Cayetano Heredia. Lima, Perú.

${ }^{2}$ Practica privada
} 
En el ciclo biológico se presentan tres estadios infecciosos: taquizoítos, bradizoítos, en quistes tisulares, y ooquistes (1). Los taquizoítos y bradizoítos en quistes tisulares, son los estadios asexuales del parásito, se encuentran en los hospederos intermediarios y son principalmente intracelulares (8-9). Los taquizoítos, son el estadio de rápida división que penetran las células hospederas por invasión activa (10), miden aproximadamente $6 \times 2$ $\mathrm{mm}$. Los bradizoítos miden de $8,1 \times 2 \mathrm{~mm}$, siendo aparentemente más delgados que los taquizoítos. Los quistes tisulares contienen entre 20 y 100 bradizoítos, son redondos u ovalados, tienen $17 \mathrm{~mm}$ de largo y 14,5 de ancho y se encuentran mayormente en el Sistema Nervioso Central (SNC). Los ooquistes se desarrollan mediante la fase sexual, llevándose a cabo en los cánidos domésticos (11) y coyotes (12); que adquieren la infección al ingerir tejidos de hospederos intermediarios con quistes tisulares, eliminado luego ooquistes no esporulados en las heces, los cuales esporulan a los tres días, produciendo dos esporoquistes con cuatro esporozoitos (1). Los ooquistes son esféricos miden 11,7 x 11,3 mm, su pared es lisa y transparente mide desde 0,6 hasta 0,8 $\mathrm{mm}$ de grosor (13).

Seroprevalencias en caballos frente a Neospora, han sido reportadas en Argentina, Brasil, Estados Unidos, Francia, Corea del Sur, Chile y Turquía empleando las técnicas de Inmunofluorescencia indirecta (IFAT) y el Test de Aglutinación, mostrando una prevalencia desde 2\% (4/191) hasta 32\% (47/145). En la actualidad es escasa la información sobre la patogenicidad y prevalencia de Neospora en caballos, se describen sintomatología nerviosa, mieloencefalitis (14) que incluyen debilitamiento, pérdida de la propiocepción, cambios conductuales, ataxia (15); así como se identifica en caballos sintomatológicamente sanos (16). Asimismo, se ha demostrado la transmisión transplacentaria y una relación entre presencia de Neospora y aborto tardío en esta especie (17). Cabe mencionar que estudios moleculares han demostrado que Neospora hughesi, es la especie que infecta a los caballos; sin embargo, en los últimos años la identificación de anticuerpos séricos corresponden a N. caninum (1).

El Perú cuenta con una población de 2175730 équidos de los cuales 1062154 son caballos (18). A diferencia de otras especies existe muy poca información sobre la situación zoosanitaria de los equinos a pesar de que la crianza y producción de caballos de carrera propicia un gran aporte a la economía generando empleo, bienes y servicios o ingresos por la exportación. El caballo pura sangre inglés es una de las razas más valiosas del mundo. A partir de ella se ha formado una inmensa industria dedicada a la cría y a las carreras. Existen trabajos sobre abortos en caballos de carrera en el Perú (19), pero sin considerar a Neospora como posible agente causal, a pesar de que éste se encuentra asociado con problemas reproductivos (mortinatos, fetos momificados) en el ganado bovino y ha sido reportado como agente causal de abortos en bovinos, llamas y alpacas (7, 20). Por tanto, el presente estudio tuvo como objetivo detectar la presencia de anticuerpos séricos frente a $N$. caninum en caballos de carrera del Hipódromo de Monterrico como primer paso para posteriormente evaluar su presencia en equinos de Lima.

\section{MATERIAL Y MÉTODOS}

\section{Lugar de estudio y procedencia}

El presente estudio fue realizado con caballos Pura Sangre de Carrera procedentes del Hipódromo de Monterrico, ubicado en el distrito de Santiago de Surco, departamento de Lima, donde existe una población aproximada de 1600 caballos distribuidos en diferentes caballerizas.

Las muestras de sangre fueron analizadas en el Laboratorio de Parasitología de la FAVEZ - UPCH.

\section{Tamaño de muestra}

El diseño corresponde a un estudio descriptivo de corte transversal, donde el tamaño de la muestra fue determinado usando la fórmula para detección de una enfermedad (21). El tamaño mínimo de las muestras fue calculado en 119 animales, pero se tomaron muestras de 163 caballos, siendo las variables a considerar el sexo, edad y procedencia (ubicación de nacimiento de los caballos). Todos los animales estudiados se encontraban bajo supervisión médica veterinaria en el Hipódromo, no habiéndose registrado antecedentes de problemas neurológicos.

\section{Colección de muestras}

La obtuvo muestras de sangre por punción de la vena yugular, empleando agujas de $21 \times 1 \frac{1}{2}$, en tubos Vacutainer al vacío, sin anticoagulante y estériles. Las muestras fueron transportadas al Laboratorio de Parasitología de la FAVEZ- UPCH, donde se procedió a su centrifugación a $3000 \mathrm{rpm}$ por 10 minutos para 
la obtención del suero. Los sueros obtenidos fueron trasvasados a tubos Ependorf estériles de $1.5 \mathrm{ml} \mathrm{y}$ almacenados $\mathrm{a}-20^{\circ} \mathrm{C}$ hasta su procesamiento.

Paralelamente a la recolección de muestras, se levantó información situacional y epidemiológica de los animales del lugar.

\section{Procesamiento de las muestras}

Las muestras se analizaron mediante la prueba de IFAT, utilizando el siguiente protocolo:

Dilución de sueros a una proporción de 1:100 (22) en solución fosfato básico de sodio (PBS).

En láminas de múltiples pocillos, conteniendo $10^{7}$ taquizoítos fijados de $N$. caninum (Cepa NC-1), se añadió la dilución de los sueros y se incubó por 30' a $37^{\circ} \mathrm{C}$ en una cámara húmeda. Posteriormente, se lavó con PBS 1X durante 10 minutos, con ligera agitación. Las láminas fueron secadas a temperatura ambiente y luego se colocó $9 \mu \mathrm{l}$ del conjugado Anti equino IgG FITC (Lab. VMRD) en cada pocillo. Se incubó por $30^{\prime}$ a $37^{\circ} \mathrm{C}$ en cámara húmeda.

Luego, se procedió al lavado rápido de las láminas en un vaso Coplin con agua destilada e inmediatamente se trasvasó a otro vaso Coplin conteniendo una solución de azul de Evans (1:100), para su lavado en agitación lenta, por 10 minutos.

Finalmente se secaron a temperatura ambiente y se colocó una gota de líquido de montaje (FluoprepBayer), para su observación en el microscopio de fluorescencia y la lectura correspondiente.

Se consideró una reacción positiva la observación de fluorescencia completa en la dilución $\geq 100$

Titulación de anticuerpos especificos frente a $N$. caninum: Los sueros que resultaron positivos en la primera prueba fueron titulados con diluciones seriadas desde $1: 100$ hasta 1:3200 (22).

\section{Análisis de datos}

Los resultados fueron expresados en forma porcentual y la posible asociación entre las diferentes variables (edad, sexo y lugar de procedencia del animal) se analizó mediante pruebas de asociación (Chi cuadrado) utilizando el programa estadístico SPSS 15,0

\section{RESULTADOS Y DISCUSIÓN}

En nuestro país no existe una adecuada información zoosanitaria en equinos, ni se ha registrado en los últimos 10 años el hallazgo de problemas nerviosos y reproductivos en esa especie. Con la finalidad de contribuir con la evaluación sanitaria de los caballos es que se realizó una toma de muestras serológicas para detectar anticuerpos séricos frente a $N$. caninum en caballos de carrera.

De 163 caballos muestreados, 19 resultaron positivos, detectándose la exposición en 11,66 \pm $4,93 \%$ (Tabla 1), resultados que concuerdan con estudios realizados en Estados Unidos, 11\%, 59/536 y $23 / 208(22,23)$; siendo estos bajos, comparados a los resultados reportados por (24) en Chile con una prevalencia de $32 \%$ (47/145); sin embargo, esto puede deberse a que los animales utilizados en este último estudio eran de diferentes razas, diferentes regiones del país y diferentes condiciones zoosanitarias y a que el tipo de prueba serológica utilizada (NAT) tiene una especificidad menor a $97 \%$ (25), con respecto a la prueba usada en el presente trabajo. Cabe recalcar que la técnica IFAT es considerada una prueba diagnóstica gold-estándar para $N$. caninum, debido a que presenta una sensibilidad de $98 \%$ y una especificidad de $99 \%$ (25), y muestra menor número de reacciones cruzadas

Tabla 1. Distribución de caballos con anticuerpos séricos frente a $N$. caninum según sexo (Lima, 2010)

\begin{tabular}{|c|c|c|c|}
\hline \multirow{2}{*}{$\begin{array}{l}\text { Estrato de } \\
\text { Estudio }\end{array}$} & \multirow{2}{*}{$\begin{array}{c}\text { Total de } \\
\text { Animales (n) }\end{array}$} & \multicolumn{2}{|c|}{ Positivos } \\
\hline & & $\mathrm{N}^{\circ}$ & $\% \pm$ I.C. \\
\hline Macho & 87 & 10 & $11,49 \pm 6,7$ \\
\hline Hembra & 76 & 9 & $11,84 \pm 7,2$ \\
\hline Total & 163 & 19 & $11,66 \pm 4,93$ \\
\hline
\end{tabular}

Tabla 2. Distribución de caballos con anticuerpos séricos frente a N. caninum según edad. (Lima, 2010)

\begin{tabular}{cccc}
\hline \multirow{2}{*}{ Estrato de Estudio } & Total de & \multicolumn{2}{c}{ Positivos } \\
\cline { 2 - 4 } & Animales (n) & $\mathrm{N}^{\circ}$ & $\% \pm$ I.C. \\
\hline 1-2 años & 44 & 6 & $13,64 \pm 10,41$ \\
$>2-3$ años & 61 & 7 & $11,47 \pm 7,99$ \\
$>3$ - 4 años & 29 & 3 & $10,34 \pm 11,08$ \\
$>4$ años & 29 & 3 & $10,34 \pm 11,08$ \\
Total & 163 & 19 & $11,66 \pm 4,93$ \\
\hline
\end{tabular}


con otras coccidias, cuando se les compara utilizando otras técnicas (26-27). Además la técnica IFAT es la prueba óptima para estudios de detección serológica de Neospora en equinos (28). Por otro lado la normalización de la técnica; así como el punto de corte (1:100) usado en el presente estudio, nos brindan una alta especificidad, disminuyendo la probabilidad de las reacciones cruzadas (22).

En lo que respecta al sexo, se observó una frecuencia de $11,49 \%$ en machos y $11,84 \%$ en hembras (Tabla 1) no observándose diferencias estadísticamente significativas entre ellas; datos que coinciden gcon el estudio realizado por Kligher et al., en donde tampoco se encontraron diferencias entre sexos (29).

En relación al grupo etario, se halló una frecuencia que varía de $10,34 \%$ hasta $13,64 \%$, siendo la más elevada en equinos de 1 a 2 años de edad (Tabla 2), lo cual posiblemente se deba a que la transmisión vertical es la más importante para la infección de $N$. caninum. Estudios en bovinos demuestran que hay frecuencias altas en animales de menor edad (3031). Sin embargo, en el presente estudio no hubo asociación estadísticamente significativa entre la variable edad y los animales positivos a $N$. caninum, coincidiendo con trabajos realizado en camélidos sudamericanos $(6,32-33)$. Por otro lado, no coinciden con lo reportado por Kliger et al. en caballos, quien encontró una asociación estadísticamente significativa lineal entre edad y seropositividad a Neospora (29). Esta diferencia posiblemente se deba a que el estudio de Kliger se diseñó para evaluar los factores de riesgo, mientras que en el presente estudio fue un hallazgo complementario.

Tabla 3. Distribución de caballos con anticuerpos séricos frente a $N$. caninum según procedencia (Lima, 2010)

\begin{tabular}{lccc}
\hline \multirow{2}{*}{$\begin{array}{c}\text { Estrato de } \\
\text { Estudio }\end{array}$} & $\begin{array}{c}\text { Total de } \\
\text { Animales (n) }\end{array}$ & & \multicolumn{2}{c}{ Positivos } \\
\cline { 3 - 4 } Norte del Perú & 60 & 11 & $\% \pm$ I.C. \\
Centro del Perú & 26 & 2 & $11,69 \pm 12,33 \pm 9,79$ \\
Sur del Perú & 50 & 5 & $10,00 \pm 8,31$ \\
Del Exterior* & 27 & 1 & $3,70 \pm 7,12$ \\
Total & 163 & 19 & $11,66 \pm 4,93$ \\
\hline
\end{tabular}

*Procedentes de Argentina, Chile, Estados Unidos, Canadá.
Tabla 4. Titulación de anticuerpos, según diluciones seriadas (Lima, 2010)

\begin{tabular}{ccc}
\hline Dilución & Muestras positivas & Frecuencia (\%) \\
\hline $1 / 100$ & 4 & $21(4 / 19)$ \\
$1 / 200$ & 3 & $16(3 / 19)$ \\
$1 / 400$ & 3 & $16(3 / 19)$ \\
$1 / 800$ & 4 & $21(4 / 19)$ \\
$1 / 1600$ & 4 & $21(4 / 19)$ \\
$1 / 3200$ & 1 & $5(1 / 19)$ \\
Total & 19 & $100 \%$ \\
\hline
\end{tabular}

En relación a la procedencia, se observó una mayor frecuencia $(13,23 \%)$ en los animales nacionales que en los importados (3,7\%; tabla 3$)$, sin que estos valores sean estadísticamente diferentes. En el grupo de los nacionales tendieron a ser más aquellos procedentes del norte; sin embargo, se anota que la mayor parte de los animales muestreados en el presente estudio (60/163 animales) eran procedentes de criaderos del norte y todos ellos de una misma provincia, Sayán; lo cual pudo influir en la positividad. Hasta el momento no se cuenta con ningún estudio previo que considere la variable procedencia en caballos frente a $N$. caninum.

En lo que respecta a la titulación de anticuerpos de las muestras positivas (Tabla 4), posiblemente todos aquellos animales que presentan títulos mayores desde $1 / 800$ hasta $1 / 3200$ se encontrarían en una fase de reactivación o reinfección de la enfermedad produciendo una respuesta de su sistema inmune con alta producción de títulos de inmunoglobulinas demostrable a la titulación de anticuerpos; mientras que los animales que presentan títulos de anticuerpos desde $1 / 100$ hasta $1 / 400$, se encontrarían en una fase crónica, mostrando títulos de inmunoglobulinas no tan altos. Al respecto, no hay estudio previo de $N$.

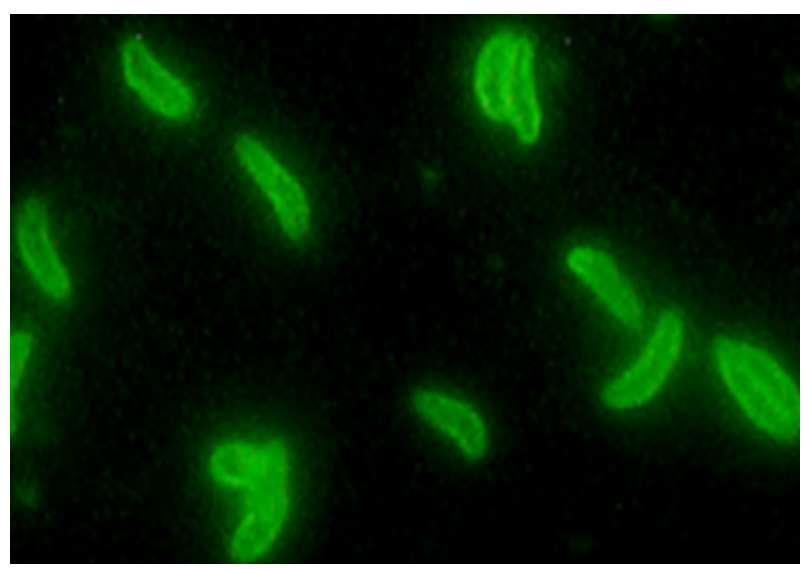

Foto 1. Muestra Positiva a $N$. caninum mediante IFAT en caballos (taquizoito Nc-1. 400X) 
caninum en caballos donde se evalúe la titulación de anticuerpos séricos y las fases de enfermedad, siendo este el primer estudio.

La presencia de Neospora en caballos se ha relacionado a problemas del Sistema Nervioso Central como mieloencefalitis equina $(14,34)$ el cual se relaciona con problemas que incluyen debilitamiento, perdida de la propiocepción, cambios conductuales y ataxia (15). También se ha relacionado con abortos, mortalidad neonatal y perinatal en diferentes estudios $(23,35)$. Veronesi et al. demostraron una correlación positiva entre presencia de Neospora $s p$ y aborto (O.R 1,2, 95\%), siendo esta relación más fuerte en abortos tardíos (O.R 2,3\%, 95\%) (17). Sin embargo, estudios realizados por Ciaramella et al. y Kilbas et al. muestran que la sero-reacción no siempre está presente y asociada con sintomatología $(36,16)$. Los animales empleados en el presente estudio no manifestaron signos de infección por $N$. caninum.

El presente trabajo es el primero en detectar la presencia de anticuerpos séricos a $N$. caninum en caballos del país, por lo cual se considera que los resultados reportados aquí son de importancia cuando se estén evaluando problemas reproductivos (como retorno a celo, abortos) en yeguas, así como problemas nerviosos en caballos. Cabe recalcar, que en los últimos años se ha demostrado el rol que desempeña Neospora $s p$ en el desarrollo de mieloencefalitis equina (14); sin embargo, no es sino hasta este momento en que es considerado entre los diagnósticos diferenciales de enfermedades neurológicas en caballos, por lo cual es necesario continuar los estudios en esta especie en el país.

\section{CONCLUSIONES}

Se detectó, por primera vez en el Perú, la presencia de anticuerpos séricos frente a Neospora caninum en caballos.

El 11,66\% (19/163) de los caballos de carrera tuvieron exposición a $N$. caninum, desarrollando anticuerpos frente al protozoo.

No se encontró asociación estadística significativa entre las variables sexo, edad y procedencia con la presentación de anticuerpos séricos frente a $N$. caninum

Se recomienda realizar mayores estudios sobre todo en haras, así como criaderos de Caballos de
Paso, con la finalidad de determinar la prevalencia y relación de este parásito con abortos y con problemas nerviosos.

\section{Correspondencia}

Marcos Enrique Serrano Martínez

Correo electrónico: enrique.serrano@upch.pe

\section{AGRADECIMIENTO}

Los autores agradecen al Dr. Luis Miguel OrtegaMora del grupo SALUVET de la Universidad Complutense de Madrid-España, por la donación de la cepa NC-1 de Neospora caninum y por su incondicional apoyo para la realización de esta investigación

\section{REFERENCIAS BIBLIOGRAFICAS}

1. Dubey JP. Review of Neospora caninum and neosporosis in animals. Korean J Parasitol. 2003; 41(1): 1-16.

2. Dubey JP, Carpenter JL, Speer CA, Topper MJ, Uggla, A. Newly recognized fatal protozoan disease of dogs. J Am Vet Med Assoc. 1988; 192(9): 12691285.

3. Basso W, Venturini L, Venturini MC, et al. First isolation of Neospora caninum from feces of a naturally infected dog. J Parasitol. 2001; 87(3): 612618.

4. Dubey JP, Barr BC, Barta JR, et al. Redescription of Neospora caninum and its differentiation from related coccidian. Int J Parasitol. 2002; 32(8): 929-946.

5. Dubey JP, Lindsay DS. A review of Neospora caninum and neosporosis. Vet Parasitol. 1996; 67(12): $1-59$.

6. Chávez V, Serrano-Martinez E, Casas E, OrtegaMora L. Neospora caninum en Camélidos Sudamericanos Peruanos. Rev Inv Vet Peru. 2002; 13(2): 92-93.

7. Serrano-Martínez E, Collantes-Fernández E, Chávez A, Rodríguez-Bertos A, Casas-Astos E, Risco V. Evaluation of Neospora caninum and Toxoplasma gondii infections in alpaca (Vicugna pacos) and llama (Lama glama) abortes foetuses from Perú. Vet Parasitol. 2007; 150(1-2): 39 - 45.

8. Dubey JP, Schares G, Ortega-Mora LM. Epidemiology and control of neosporosis and Neospora caninum. Clin Microbiol Rev. 2007; 22(2): 323-367.

9. Speer CA, Dubey JP, McAllister MM, Blixt JA. Comparative ultrastructure of tachyzoites, bradyzoites and tissue cysts of Neospora caninum and Toxoplasma gondii. Int J Parasitol. 1999; 29(10): 1509-1519.

10. Hemphill A, Gottstein B, Kaufmann H. Adhesion and invasion of bovine endothelial cells by Neospora 
caninum. Parasitology. 1996; 112(2): 183-197.

11. Mc Allister, MM, Dubey JP, Lindsay DS, Jolley WR, Wills RA, McGuire AM. Dogs are definitive host of Neospora caninum. Int J Parasitol. 1998; 28(9): 14731478.

12. Gondim LF, McAllister MM, Pitt WC, Zemlicka DE. Coyotes (canis catrans) are definitive host of Neospora caninum. Int J Parasitol. 2004; 34(2): 159-161.

13. Lindsay DS, Upton SJ, Dubey JP. A structural study of the Neospora caninum oocyst. Int Parasitol. 1999; 29(10): 1521-1523.

14. Marsh AE, Barr BC, Madigan J, Lakritz J, Nordhausen $\mathrm{R}$, Conrad PA. Neosporosis as a cause of equine protozoal myeloencephalitis. J Am Vet Med Assoc. 1996; 209(11): 1907-1913.

15. Dubey JP, Lindsay DS, Saville WJ, Reed SM, Granstrom DE, Speer CA. A review of Sarcocystis neurona and equine protozoal myeloencephalitis (EPM). Vet Parasitol. 2001; 95(2-4): 89-131.

16. Kilbas ZG, Adanir R, Avioglu H. Seroprevalence of Neospora caninum in race horses in Ankara, Turkey. Ac Parasitol. 2008; 53(3): 315-316.

17. Veronesi F, Diaferia M, Mandara MT, et al. Neospora spp infection associated with equine abortion and/or stillbirth rate. Vet Res Commun. 2008; 32(1): 223226.

18. Instituto Nacional de Estadística e Informática. III Censo Nacional Agropecuario - Resultados definitivos. Tomo IV. Lima - Perú: Ministerio de Agricultura; 1996. p. 2407-2414.

19. Rivera H, Alvitres R, Manchego A, Sandoval N, Rosadio R. Aborto por virus herpes equino. Rev Inv Pec IVITA. 1997; 8(1): 49-55.

20. Silva P, Chávez A, Rivera H, Casas E. Seroprevalencia de Neospora caninum en bovinos lecheros del valle de Lima. Rev Inv Vet Perú. 2002; 13(2): 51-55

21. Thrusfield M. Veterinary Epidemiology. $3^{\text {rd }}$. ed. Oxford, England: Blackwell Science; 2005.p. 600.

22. Vardeleon D, Marsh AE, Thorne JG, Loch W, Young R, Johnson PJ. Prevalence of Neospora hughesi and Sarcocystis neurona antibodies in horses from various geographical locations. Vet Parasitol. 2001; 95(2-4): 273-282.

23. Cheadle MA, Lindsay DS, Rowe S, et al. Prevalence of antibodies to Neospora caninum in horses from Alabama and characterization of isolate recovered from a natural infected horse. Int J Parasitol. 1999; 29(10): 1537-1543.

24. Patitucci AN, Perez MJ, Carcamo CM, Baeza L. Presencia de anticuerpos séricos contra Neospora caninum en equinos en Chile. Arch Med Vet. 2004; 36(2): 203-206.

25. Packham A, Sverlow K, Conrad P, et al. A modified agglutination test for Neospora caninum: Development, optimization, and comparison to the indirect fluorescent-antibody test and enzyme-linked immunosorbent assay. Clin Diagn Lab Immunol. 1998; 5(4): 467-473.

26. Trees AJ, Guy F, Tennant BJ, Balfour AH, Dubey JP. Prevalence of antibodies to Neospora caninum in a population of urban dogs in England. Vet Rec. 1993; 132(6): 125- 126.

27. Dubey JP, Lindsay DS, Adams DS, et al. Serologic responses of cattle and other animals infected with Neospora caninum. Am J Vet Res. 1996; 57(3): 329336.

28. Packham AE, Conrad PA, Wilson WD, et al. Qualitative evaluation of selective tests for detection of Neospora hughesi antibodies in serum and cerebrospinal fluid of experimentally infected horses. J Parasitol. 2002; 88(6): 1239-1246.

29. Kliger EB, Shkap V, Baneth G, Mildenberg Z, Steinman A. Seroprevalence of Neospora spp among asymptomathic horses, aborted mares and horses demostrating neurological signs in Israel. Vet Parasitol. 2007; 148(2): 109-113.

30. Dyer RM, Jenkins MC, Kwok OC, Douglas LW, Dubey JP. Serologic survey of Neospora caninum infection in a closed dairy cattle herd in Maryland: risk of serologic reactivity by production groups. Vet Parasitol. 2000; 90(3): 171-181.

31. Pereira-Bueno J, Quintanilla-Gozalo A, Pérez-Pérez $\mathrm{V}$, et al. Evaluation by different diagnostic techniques of bovine abortion associated with Neospora caninum in Spain. Vet Parasitol. 2003; 111(2-3): 143-152.

32. Moya R, Chavez A, Casas E, Serrano-Martínez E, Falcón N, Pezo D. Seroprevalencia de Neospora caninum en llamas de la provincia de Melgar, Puno. Rev Inv Vet Peru. 2003; 14(2): 155-160.

33. Casas G, Chávez A, Casas E, et al. Presencia de Neospora caninum en llamas de una empresa ganadera de la Sierra Central. Rev Inv Vet Perú. 2006; 17(1): 8-13.

34. Hamir AN, Tornquist SJ, Gerros TC, Topper MJ, Dubey J. Neospora caninum-associated equine protozoal myeloencephalitis. Vet Parasitol. 1998; 79(4): 269-274.

35. Dubey JP, Porterfield ML. Neospora caninum (Apicomplexa) in an aborted equine fetus. J Parasitol. 1990; 76(5): 732-734.

36. Ciaramella P, Corona M, Cortese L, et al. Seroprevalence of Neospora spp in asymptomatic horses in Italy. Vet Parasitol. 2004; 123(1-2): 11-15.

Recibido: 01/08/2013

Aceptado: 21/11/2013 